\title{
Applying Florence Nightingale's Model of Nursing and the Environment on Multiple Drug Resistant Tuberculosis Infected Patients in the Kenyan Setting
}

\author{
Simon Macharia Kamau*, Rose Jelagat Rotich, Brigid Chemutai Cheruiyot, \\ Lily Chepketer Ng'eno \\ Department of Nursing Sciences, University of Kabianga, Kapkatet, Kenya \\ Email: smacharia@kabianga.ac.ke, rose.rotich@yahoo.com, chemutailouis@gmail.com, \\ lilyot2008@gmail.com
}

Received 1 August 2015; accepted 21 August 2015; published 26 August 2015

Copyright (C) 2015 by authors and OALib.

This work is licensed under the Creative Commons Attribution International License (CC BY).

http://creativecommons.org/licenses/by/4.0/

(c) $\underset{\mathrm{EY}}{\mathrm{i}}$ Open Access

\begin{abstract}
Nurses in many resource limited settings have mostly used the medical model which failed to answer many of their concerns in managing tuberculosis infected patients. Florence Nightingale's Model of Nursing and the Environment states that nurses manipulate and mediate the environment to put the patient in the best condition for nature to act upon. Nursing theory and models have been recognized as key components to evidence based practice today. Every nursing unit in developed countries employs at least one. Kenyan nurses need to realize this and embrace this principle. This article begins by expounding a commonly known, but not always well understood model by the founder of modern nursing, Florence Nightingale. Methodology: The current study was a review and it applied Florence Nightingale's Model of Nursing and the Environment on drug resistant tuberculosis infected patients in Kenyan. The format of this review was completed by using the authors' adapted "Advanced Theory in Nursing" coursework materials. Secondary sources and seminal works by the theorist were also scrutinized. A case scenario was embedded that was somehow typical to maximize what could be learned about this theory. Conclusion: Nightingale's model is a generic tool applicable to guide nursing care of clients infected with multiple/extremely drug resistant $\mathrm{Tb}$ with potential to improve nursing care and provide a basis for case studies.
\end{abstract}

\section{Keywords}

Nursing Theory, Nightingale, Drug Resistant Tuberculosis, Resource-Limited, Kenyan Nurses, Evidence Based Practice, Advocacy

Subject Areas: Nursing, Public Health

\footnotetext{
${ }^{*}$ Corresponding author.
}

How to cite this paper: Kamau, S.M., Rotich, R.J., Cheruiyot, B.C. and Ng'eno, L.C. (2015) Applying Florence Nightingale's Model of Nursing and the Environment on Multiple Drug Resistant Tuberculosis Infected Patients in the Kenyan Setting. Open Access Library Journal, 2: e1796. http://dx.doi.org/10.4236/oalib.1101796 


\section{Introduction}

\subsection{Why Theory}

Due to the changing and challenging nature of nursing, various theories and philosophies have been advanced to guide nursing practice, education and research. It has been said that everyday practice enriches theory and vice versa as both practice and nursing theories are guided by values and beliefs [1]. Theory helps to reframe our thinking about nursing and guides use of ideas and techniques. Theory can close the gap between practice and research and envision potentialities. While proposing her idea of practice theory, [1] provided the following concise description for a substantive theory:

"It is a theory that says; given this nursing goal (producing some desired change or effect in the patient's condition), these are the actions the nurse must take to meet the goal (produce the change)".

According to Heartland National Tuberculosis Center [2], nurses who happen to be new to Tuberculosis control and prevention face multiple challenges including: a) learning the basics of tuberculosis infection and disease diagnosis and treatment, and b) gaining problem solving skills essential to Tb case management. The general practice nurse is the first line of defence in Tb control worldwide, and this important role needs to be recognised and strengthened [3]; one way would be through nursing theory-guided practice. "Practicing nurses who despise theory are condemned to performing a series of tasks - either at the command of a physician or in response to routines and policies”, Leah Curtin, a former editor of Nursing Management made this observation $[4])$.

It was evident from literature [4] [5] that there was a gap between nursing theories for practice as taught in the classroom and actual nursing practice. Many nurses especially in resource limited settings like Kenya had little or no knowledge of nursing theories as a basis for practice, and did not knowingly apply nursing theories to practice. Literature further suggested that some of the theories as taught were inappropriate for practice in the African context [5]. According to Owino [5] there was apparently no evidence of published studies on practice outcomes of nursing theory utilization in Kenya then, and this seemed to hold true four years later today according to us (the authors of this article). These were observations by Owino et al., a Kenyan nurse who developed a grounded theory Owino's Theory: Nurse-Client Interaction for Childbirth Preparedness Analysis and Evaluation; just referred to as Owino's Theory [5].

\subsection{The Theorist}

Florence Nightingale (1820-1910) was bestowed with several honours: OM [(order of Merit (commonwealth)], RRC (Royal Red Cross), Honorary Freedom of the City of London. She came to prominence for her pioneering nursing work during the Crimean war where she tended to the wounded British soldiers. An Anglican herself, she believed that she was called to be a nurse. Though living in the $19^{\text {th }}$ century she was endowed with premodern feelings and modern ideas, which remain quite relevant today. She laid the foundation of modern nursing [6] [7]. Her work has influenced many other disciplines including mathematics, writing, public health, medical tourism, heath care legislation/ reforms, medicine, hospital architecture and the church.

She is one of the most celebrated, written about character through biographies (there are more than 300 Nightingale biographies and 16 volumes of her writings), art, theatre, poetry, and museum [7]. Queen Victoria wished aloud that she had Nightingale in her cabinet. Nursing schools, babies, buildings and streets were named after her [8].

\section{Introduction to the Model of Nursing and the Environment}

Analysis:

o Nightingale's concept model is overlapping with discrete concepts.

o Model is still applicable to practice today.

o Model is simple and easy to understand.

- Model requires the nurse to use knowledge in addition to "artistic" viewpoints. Allows intuition and personal caring to aid in patient health.

Nightingale emphasized that the person had a key role in his/her own health and that health was a function of the interaction between person, nurse and environment. The major assumption was that nurses concern was with the person in the environment and the person interacting. The laws of health as defined by Nightingale were 
those to do with keeping the person and the population healthy. She indicated that proper use of fresh air, light, warmth, cleanliness, quiet had least expense in terms of vital power.

She believed in a "healthy house" in order to prevent illness and promote wellness. Two of the elements to a healthy house that were emphasized in her theory were fresh air and sunlight. Health of houses as she prescribed were the administration of each or all of these: ventilation of patients' rooms and the larger environment, light, cleanliness, punctuality, eating of food and interpersonal milieu. The patient's capacity for self-healing was facilitated by the nurses' ability to create an environment conducive to health. Nurses on the other hand manipulate and mediate the environment to put the patient in the best condition for nature to act upon, concerning this she said, "what nursing has to do... is to put the patient in the best condition for nature to act upon him" [9]. Nurses must also be protected while they care for others [3].

5 essential elements to a "healthy house": clean air; clean water; proficient drainage; cleanliness; light.

\section{Assumptions:}

o Nurses should be educated and trained in the field and care of patients.

o Nurses should focus on environment and how to manipulate it to put patients in the best possible state to achieve health and healing.

0 The environment is essential to the health of the patient.

o Nursing and medicine are separate.

o Nursing is a science and an art.

Strengths:

o Nightingale's Model of Nursing and the Environment is easily adaptable, as well as applicable, to all patient care settings.

o Model and theory's meaning and purpose is easily understood.

o Nightingale's writings are easy to read and understand regardless of the difference in time period and changes in terminology over the years.

\section{Limitations:}

o Nightingale's environmental theory does not directly discuss the effects of the environment on patients' psychological health.

o Theory is limited but it is still effective.

Controversies:

Among some of her beliefs, here are a few that we found interesting and though we felt some would not be a reality in today's healthcare:

1) Noise — she stated patients should never be waked intentionally or accidentally during the first part of sleep. Counterargument: Today on night shift patients are woken up multiple times per night for vital signs, medications, labs etc. Patients are lucky to get two to three hour stretches of sleep during the night.

2) Variety - she believed in varying colors from flowers to plants and even rotating paintings on a regular basis. Counterargument: Hospital rooms are neutral colors and are lucky if they have a painting or a working wall clock on them. If there are flowers (or a card for that matter) in the room, they are from family, not provided by the hospital. There is actually very little "variety" in the hospital.

3) Nutrition and Food - she vowed that no business be done with patients while they are eating because that is a distraction. Counterargument: In most cases, patients are on "hospital time" when they are in the hospital and we distract them often as they eat.

4) Her philosophy about nursing as a calling. However, she may not have meant "calling" in a religious sense but having a kind of feeling for one's work - an inner sense of what is right, which she termed "enthusiasm," from the Greek ethos, having a god within. Counterargument: some people do not agree that nursing is a calling with; fewer wanting to play some of the roles she modelled for women-the obedient wife, caring sister, modest daughter and her feminist ideals (emphasis ours).

5) She was against a standardized nursing licensing exam and felt that an individual should be evaluated on their character and morals. Counterargument: This would be rather odd today, no nurse can practice without first passing a board exam and get state or national body license.

\section{Nursing and the Environment:}

Adapted from [6] [10] focuses on the patient while manipulating the environment. Nursing and the environment referred to several things: the "health of houses"; prevention of illness; promotion of health; observation of sick; "healthy house"; attention to nutrition; attention to patients and their needs. 


\section{Concepts}

o Ventilation and warming (clean air)—Should be the first and last thing that nursing should fix. Air that the patient breathes should be pure, fresh and warm.

o Clean water-water should be sanitary. Sewers should be kept separate from drinking water, and water should be purified to prevent illness

o Drainage — pipes and sewers should drain effectively. In Nightingale's time this was a real issue.

o Cleanliness-Open windows, clean dust, dispose of waste properly, clean linens, carpets and floors.

o Light—dark houses are unhealthy and poorly circulated. Sun and light were essential for proper healing of patients.

o Nursing aids in the ability of a person to maintain health and to heal, by managing the environment.

o Frequent observation and individualization per patient was necessary.

o Nursing encompasses observation and management; the environment encompasses ventilation and warming, and the health of houses.

o Nurses are to manipulate the environment and manage health. This directly affects all the concepts in Nightingales model.

\section{Tuberculosis}

Tuberculosis is a serious communicable disease. Tb control was challenged by the HIV epidemic, it had shown improvements, with key indicators such as Case Notification, Case Detection, and Treatment Successes all showing improvement before HIV came into the scene. HIV and Tb formed a lethal combination with each speeding the other's progress. From then on tuberculosis was ranked second only to HIV/AIDS among the infectious agents with highest mortality rates worldwide, 8.6 million people fell ill of $\mathrm{Tb}$ and 1.3 million died from it. Over $95 \%$ of these deaths occurred in resource constrained countries. Tb remains the leading killer of people living with HIV [11] [12].

\section{Drug Resistant Tuberculosis}

The emergence of drug resistant Tb since 2005, particularly among males, has been a key challenge. Extremely drug resistant tuberculosis (XDR-Tb) is a form of tuberculosis caused by a strain of Mycobacterium tuberculosis a gram positive bacteria that is resistant to isoniazid and rifampicin as well as any Fluoroquinolone and any of the second line injectable anti-Tb drugs. When new strains prove too clever for the two most powerful first line drugs-isoniazid (INH) and rifampicin (RIF), multiple resistant tuberculosis (MDR) emerges, these drugs that were once effective become worthless against this strain of tuberculosis. Drug Resistant-Tb is confirmed through laboratory tests that show that the infecting isolates of Mycobacterium tuberculosis grow in vitro in the presence of one or more anti-tuberculous drugs. Two different categories of drug resistance have been established: Mono resistance is resistance to only one anti-Tb medication while Poly-resistance involve two/more drugs other than the combination of Isoniazid/Rifampcin (INH/RIF). Access to quality second line drugs as well as laboratory capacity for second-line drug susceptibility testing presents a formidable challenge for programs in low resource settings in resource-limited settings. Quality second line drugs are expensive, less available take longer, even up to two years, with a high likelihood for drug toxicity, further resistance and defaulters [11] [12].

In 1993 the WHO declared Tb a global emergency. It was interesting that even though only 10\% of those exposed to Tb became infected, one-third of the world's population were infected with the bacterium that causes Tuberculosis, meaning that one third of the world's population had latent TB, which meant they have been infected with TB but aren't (at least not yet) ill with the disease. Out of 3.7\% of new Tb diagnosed cases were multiple drug resistant (MDR-Tb) with a relapse rate of approximately 20\%. Former Soviet Union countries ranked the highest with cases of extremely drug resistant tuberculosis (XDR-Tb) worldwide. Kenya was ranked $13^{\text {th }}$ in the list of 22 category of "high Tb burden" countries worldwide. According to WHO, Kenya had an estimated 2300 cases of multiple drug resistant (MDR-Tb) in 2007. Current figures by National Tb and Leprosy Program, Kenya, there were 15 new multiple drug resistant (MDR-TB) cases are diagnosed monthly in Kenya. This information was released during the world Tb day marked on March $24^{\text {th }}$, 2015. World Tb Day served to promote advocacy for prevention, screening, and treatment of tuberculosis. "TB has no borders, anyone can contract $T b$. The healthy, the young, no one is immune" [13]. 
One in ten of all MDR-Tb cases are extensively drug resistant (XDR-Tb). Resistance often develops in areas with poor $\mathrm{Tb}$ control programmes where: $\mathrm{Tb}$ treatment was poorly managed, when patients do not complete their full course of treatment, when incorrect dosages were prescribed or when there was a break in drug supply [11] [12] [14].

The African Region accounted for over $80 \%$ of the Tb cases among people living with HIV and since higher mortality from MDR-Tb and XDR-Tb had been documented in HIV-positive patients [11]. Some of HIV patients were co-infected with MDR, XDR Tb therefore collaborative activities were widely implemented [12] [15].

In Kenya, patients have free access to diagnosis and Tb treatment services from public health facilities under the National Tb and Leprosy Program (NTLP). Ordinarily Tb treatment under directly observed treatments (DOTs) had two phases: an intensive (initial) phase, which comprised the first 8 weeks for new cases and twelve weeks for retreatment cases, and a continuation phase of $4-6$ months immediately following the intensive phase [12].

Moi Teaching \& Referral Hospital (MTRH) in Eldoret, Kenya had a standard model in the management of MDR-TB according to WHO Green Light Committee on management of MDR/XDR Tb [16]. WHO established the Greenlight Committee in the year 2000. This committee works with programs and pharmaceutical companies to secure the necessary drugs at $99 \%$ less than the open market price. It costed an average 1.2 Million Kenya Shillings (equivalent of 10, 200 USD) to treat one patient with resistant Tb according to [17] [18] WHO 2014 estimates.

The Moi Teaching \& Referral Hospital (MTRH) in Eldoret, the second largest hospital in the country in 2010 reported that $79 \%$ of notified Tb patients tested HIV positive and 37\% of HIV positive Tb patients were accessing Highly Active Anti-Retroviral Therapy (HAART). By then the centre had 11 multiple drug resistant Tb cases (six of them on home care) and 1 extremely drug resistant Tb patient (the only case known in the country then) who was being managed in the isolation ward.

\section{Application of Theory to Practice}

The Isolation wards and the homes where drug resistant $\mathrm{Tb}$ infected patients were managed need to meet the 5 essential elements to a "healthy house" namely: clean air; clean water; proficient drainage; cleanliness; light.

Nightingale talked about observation as a reliable means of obtaining and verifying knowledge. One of key determinants to $\mathrm{Tb}$ management success involves high level of case detection which goes with keen observation.

Nightingale was frequently seen making rounds and documenting observations at night carrying an oil lamp thus she was fondly referred to as "Lady with the Lamp" [19]. Tb treatment is a strict six month drug regimen provided to patients with support and supervision to ensure adherence through directly observed dose therapy (DOTS) - an observer watches the patient swallow the medicines for adherence and side effects management [3]. With MDR-Tb infected patients usually at $3^{\text {rd }}$ to $4^{\text {th }}$ month of treatment, sputum should have converted to negative. Conducting routine drug susceptibility testing for all TB cases allows early identification of drug resistance in the population at greatest risk. Utilizing a patient centred nursing process approach, case finding and patient holding as highlighted in the International Council of Nurses (ICN) manual in many ways recognized Nightingales emphasis on strict observation and documentation.

Nightingale did a lot of documentation of her thoughts, her memoirs form a solid part of the history of modern nursing (Florence Nightingale, Notes on Nursing 1860/1969) as well as influencing other fields such as advocacy, health care policy, statistics and public health. Nothing can take the place of monitoring and evaluation in the management of $\mathrm{Tb}$. Just like Nightingale did, keeping a journal, logging in and proper documentation of Tb issues by the nurse and to some extent (emphasis ours) through some training of the client are necessary competencies. She underscored the critical role of outcome documentation. Monthly Tb reports have to be submitted on or before the $5^{\text {th }}$ of each month upwards from $1^{\text {st }}$ level (community) to facility level—Sub CountyCounty-National Tb and Leprosy program (NTLP) to the global level [20]. Data is analysed to give vital statistics. This way we can monitor the clients at risk of developing MDR/XDR Tb and pre-empt it where possible. Nurses must constantly do evaluation and reassessment to ensure appropriate care at each stage to enhance the patient's adherence to $\mathrm{Tb}$ treatment protocols.

Nightingale argued using statistics, to prove that decreasing mortality would cost less money... for patients to heal translating into what we would now consider as evidence-based practice [7]. She ably plotted a polar pie 
chart on the Crimean battle hospitals mortalities significant decline (from $42 \%$ to $2 \%$ ) as result of her interventions (mainly by improved hygiene, and advocacy by calling upon the British Sanitary Commission). Charts continue to be a visual way of understanding data we still use to show prevalence rates, new cases, Tb progression to non-infective condition; sputum conversion from smear positive to smear negative. In some parts of West Pokot County in northern Kenya, a whole village could be Tb infected: with 800 new TB cases diagnosed annually and a Tb prevalence rate of 223 per 100,000 (the projected County population in the year 2012 was 562,845 people) [21]. Alupe Leprosy Centre in Busia and Tb "Manyattas" (some kind of isolation traditional dwellings within the villages of Sigor region of West Pokot County) have retained their utility value among the communities. Every year receiving thousands of medical tourists.

\subsection{Applying Model of Nursing and the Environment in Control and Prevention of Tuberculosis}

The anti-contagionism view which Nightingale apparently subscribed to postulated that some diseases were communicable and could spread by pollution of the air we breathe. Counterargument: Contagionists on the other hand believed diseases only spread through direct contact, something Nightingale opposed.

She did say that sufficient levels of contaminants could induce endemic or epidemic ills. Tb is mainly transmitted by droplet airborne from person to person supporting the anti-contagionism viewpoint. Undetected cases continue to transmit since a person only needs to inhale a few of these organisms to become infected. This knowledge comes in handy when we consider cough etiquettes-avoiding risky behaviours like spitting, discouraging open coughing, use of disposable tissues, spitting into tight fitting sputum mug, proper sputum disposal (bio-hazards) by burying or burning. Observation of universal precautions, Infection Prevention Practices and Control Protocols (IPPC), hand washing, provision of additional antiseptics such as hand sanitizers [22].

In anti-contagionists' view; in order to prevent the spread of $\mathrm{Tb}$ to others it was advisable to avoid overcrowding (e.g. church etc.) for $\mathrm{Tb}$ this would be until sputum conversion form +ve to -ve. To avoid contact time with other clients it is necessary to reduce waiting time through triage. Some African cultures encourage relatives to stay in when their significant other has been hospitalized, however it's discouraged for lay caretakers to stay overnight for an MDR/XDR Tb patient and in any case $N 95$ masks must be worn by all attending to including visitors [22]. When there happened to be $\mathrm{Tb}$ in one of the adults, there was a likely risk of household exposure to children and other relatives. For children the effectiveness of vaccination against the disease was critical.

Those who are in close contact for sustained periods of time are most at risk and these are often the children of those with the disease. WHO reported that in 2013 about 53 million children under 15 were living with latent TB infection, a condition that can develop into active $\mathrm{Tb}$ at any time [22]. Findings suggested that about 7.6 million children younger than 15 in 22 "high burden of Tb" countries became infected in 2010. Of these nearly 651,000 developed the disease [18] [23].

Fresh air and light as advocated by Nightingale play a key role in $\mathrm{Tb}$ care. Tb bacterium are sensitive to light and do very well in stuffy poorly lit rooms. As much as possible patient is to stay outdoors. The rooms must have wide openable windows. She emphasized importance of variety since the "nerves of the sick suffer from seeing the same walls, same ceilings same surroundings". The need for an outdoor, pleasant surroundings, sunlight, and fresh air perhaps meets this goal. A good example that contravenes Nightingales principles are prisons in Kenya. They are extremely congested such that the holding grounds which were meant to have 500 inmates can have four times that number. Tb thus is high among inmates. Prisoners in cells share the same poorly ventilated air for extended periods of time, and movement within the prison is limited to some limited perimeter. Prisoners found that it was a big privilege to be allowed some few minutes of sunlight per day, one politician claimed "some prisoners were locked in the cells for months without seeing the sun" Kenya National Assembly official record [24].

One of the strategies used during Nightingale's time was quarantine. To keep the disease away from non-infected areas. The management of XDR Tb will remain a challenge as there is no effective treatment and isolation for indefinite period could raise human rights issues. Nevertheless, for MDR/XDR Tb we need to isolate those who meet a stringent criteria such as: non-adherence, refugee camps. Kenya is host to the largest refugee camps in the world of about 630,000 refugees in Dadaab and Kakuma. Another common problem that might be mitigated by admitting patient into the isolation ward is that of long distances the patient has to cover to reach facility (on average most are 5 to $10 \mathrm{~km}$ away or further for nomadic communities). Even at home a separate room for the patient is advisable during intensive phase of treatment [12] [20]. 
Kenyatta National Hospital (KNH) had closed the isolation ward for some years and it took some activism and media report to have it repossessed from the Nairobi Hospice in September 2014. This was significant in the wake of the Ebola threat that had seriously affected a number of West African countries of Liberia and Sierra Leone among others. Reports by Save the Children International [25] indicated that in Sierra Leone a "terrifying rate" 5 people were getting infected with Ebola virus disease every hour which overwhelmed the country's health care system.

The Nightingale model advocated for proper diet selection and administration. Tb patients usually have poor appetite, some of the drugs they take also cause them nausea and vomiting as side effects. Therefore a collaborative food drug plan is necessary: eat pleasant healthy balanced diet, modified where necessary of affordable locally available food, drink only safe water. Just as Nightingale advised on monitoring of patient's expenditure of energy, regular anthropometric measures monitoring like weight and body mass index are done as most Tb patients tend to waste away. Indeed weight gain was an important prognostic indicator for Tb.

Going back a little more on the concept of ventilation; ventilation of dwellings was a key concept in Nightingale's model [26]. She wrote, "I do think that the feeling of fresh air and warm sunlight on patient's face raises their spirit and has an effect on the psyche. The lack of which has also contributed to delirium in some hospitalized patients”. Preferably we should have natural lighting and where possible fit UV lights into the room. Tb patients experience night sweats and need pure fresh air which is circulating adequately, perhaps what Nightingale had in mind. In the rural areas and much of the informal (slums) settlements in resource limited settings the houses are overcrowded and many lack windows. The traditional African hut had one or two "peeping" holes, which acted as windows. The hut is commonplace wherever one goes into the rural Africa. Many people do not have separate room for fireplace. All these compromise on ventilation.

Successful tuberculosis treatment depends on more than chemotherapy and requires specific clinical and social frameworks based on an individual patient's circumstances [27]. Interpersonal mileau was referred to in the Nightingale model [28]; the role of the community in-psychosocial support to encourage patient to finish treatment, social support (i.e., assistance and emotional support from others); active case finding; cough monitors; management of contacts-tracing, follow up/visiting patients home every 3 months for 24 months to ascertain close contacts even the asymptomatic ones. In case of defaulter tracing, visit patient's home within 24 hours. In the public/private sector mix, there are now stickers on public transport in Kenya commonly known as "matatus". One read: "Stop Tb, open windows for air circulation". The Preferred mode of transport for Tb patient is the "bodaboda" namely bicycle or motorcycle seat-taxis. Some ideas for incentives to motivate the patient to adhere to treatment are known to be effective and enhance the patient/nurse relationship: support groups; award ceremonies on successful completion of treatment; reimbursement for travel, food, visits, and reminder alert reminder phone calls [3] [12].

\subsection{Applying Model of Nursing and the Environment on Advocacy}

Nightingale left us the legacy of connecting caring with activism [9]. Florence Nightingale wrote, "It may seem a strange principle to enunciate as the very first requirement in a hospital that it should do the sick no harm. It is quite necessary, nevertheless, to lay down such a principle” [29]. Activism in primary caring promotes exposing, provoking, and unbalancing the social power that maintains people in a state of disease, while simultaneously nurturing caring [30].

When she was nearing the end of her life, Florence Nightingale said: "May we hope that when we are all dead and gone, leaders will arise who have been personally experienced in the hard, practical work, the difficulties and the joys of organizing nursing reforms, and who will lead far beyond anything we have done" [31].

It is worth noting that just as MDR Tb is a relatively new threat to health it is an entirely man-made phenomenon resulting mainly from badly organized Tb-control efforts and poor therapeutic practices of the past. Activism provides the knowledge and means of redressing the social inequalities that maintain an environment of disease [30]. Activism and political reform in Tb care today can be seen in the following scenario:

In October 2011, a HIV-infected Nairobi woman was diagnosed with XDR-Tb while already receiving her treatment at the Kenyatta National Hospital for MDR-Tb. Treatment was provided by the hospital; however, she was prescribed three additional medicines that she had to buy herself, to supplement the regimen. Following a public outcry over the handling of the patient's case, the government stepped in to pay for all her medication [32] [33]. 
Mismanagement of $\mathrm{Tb}$ treatment is the primary cause of resistance therefore uninterrupted drug supply is a must. Pointing out the need for bold policy decisions urging the government to invest in country's Tb programme: equipping to diagnose, treatment and care of XDR-Tb patients in Kenya. Everything possible must be done to ensure effective case detection and treatment success by well-run control programs otherwise MDR-Tb will become a major public health problem worldwide [33].

High turnover of health care staff including those in central $\mathrm{Tb}$ units is one of the main challenges to $\mathrm{Tb}$ control. Nurses working with patients infected with MDR/XDR or even suspect Tb need to be educated about the occupational risk, best-practice recommended methods of protection as they take care of $\mathrm{Tb}$ infected patients and should have HIV tests regularly. Those found positive are not work there but opt to work in less risky environment. There is a high demand for training of health care workers in this area [3]. The relatives often lack the necessary knowledge and skills about how to support and care for sick at home. Women in Africa often share a disproportionate share of care giving than men.

If the reader happens to be coming from developed countries, it would be fair to state that there are disturbing "standard" third-world conditions where majority of our patients live. Uncertainty is a fact of life in many a patients' environment: for example, the fact that there is lack of hot, running water; that the toilets do not flush; that the mosquitoes are malaria-ridden. If indeed fear of being ostracized for being $\mathrm{Tb}$ infected is real then the stigma for MDR/XDR Tb infected is worse. Serious health disparities with majority of the population not having any form of medical insurance. The professional or lay care giver often times learns how to thrive in these prohibitive contexts e.g. how to "perform care with nothing" which might mean anything from doing without some necessary protective gear to having to improvise on some basics. Nightingale worked in worse surroundings, so we can do better.

\subsection{Case Study}

Scenario-Mrs. F. Chepkemoi (not her real name) is a $61 \mathrm{y} / \mathrm{o}$ female who has been admitted for acute confusion, dehydration, wasted, urinary tract infection, malnutrition, and wound care. The patient is widowed, mother of two grown up children, lives on her own in single rented room at Langas Estate, Eldoret. Was brought to the Casualty department after a neighbour checked on her and found her in that state.

Subjective-Patient complained of itching and of being thirsty, unable to eat. Has had fever and night sweats, weight loss, and productive cough.

Objective-Patient has poor hygiene, and appears to be restless.

Significant past medical history-Had a history of Pulmonary Tb, declared cured on Catt 1 (notes indicated she had 2 cultures and 2 smear consecutively negative converted). She was HIV negative.

Assessment-Vital signs are: B/P 90/60, HR 110, T $39.8^{\circ} \mathrm{C}, \mathrm{RR}_{34}, \mathrm{SO}_{2} 87 \%$, Patient alert and oriented to place and person only. Pale + , Skin tenting, mucous membranes dry. Red and raised rash to extremities, stage II ulcer to coccyx. Lymphadenopathy axillary nodes, Weight $44 \mathrm{Kgs}$, Height 5'1". Patient is ambulatory, unsteady gait noted. Respiratory system: difficulty in breathing, reduced chest wall movement the right side with coarse crepitations. Chest X-ray showed bullous lesion, with right lower lobe consolidation. Sputum smear positive. Culture and sensitivity later showed resistance to INH and Rifampcin.

Suspect-MDR-TB.

Plan—Care for her in the isolation unit for the first 3 months and do observed dose therapy. Administer IV fluids and medications as ordered. Start Regimen Step 1 to 3 agents. Schedule nutritional consult with dietician. Establish hygiene care routine. Social services evaluation for living conditions assessment. Routine skin assessment and wound care. Handle the issues of myths on the threat of MDR TB that might lead to stigma such as "its incurable", but nevertheless control the number of contacts. Turn off fluorescent lighting and use natural light and lamps for patient comfort. The isolation ward was a prototype in the manner of Nightingale's "healthy house": proficient drainage, clean air, no dust, adequate ventilation, natural light. After 3 weeks fever had subsided, patient had gained weight and anorexia had improved. The case was an ongoing concern by the time of submitting article.

\section{Conclusion}

The general practice nurse is the first line of defence in $\mathrm{Tb}$ control worldwide, since Tb (including MDR-Tb) is a treatable and curable disease. This important role must be recognised and strengthened [3]. One way is through 
nursing theory-guided practice. We therefore submit that Florence Nightingale's Model of Nursing and the Environment is a generic tool that would be applicable to nursing care of clients with MDR/XDR Tb in Kenya and other resource constrained settings. It is therefore a great resource. Several case studies based on this model would be possible. Hopefully, readers will be directed to seek further information, some of which are contained in the links below in order to fully appreciate the utility value of this approach to nursing care. Link like these ones [26] [34] [35] would be a great place to begin with. Nurse managers in charge of nursing units (including Chest Clinics and $\mathrm{Tb}$ units) are encouraged to consider adopting on a minimum one relevant nursing theory/ model as a step towards evidence based practice.

\section{Acknowledgements}

Presenters and discussants, Sue Hagedorn PhD \& Geer Betty PhD NURS 6012: Advanced Theory in Nursing., Spring 2014 Semester, University of Colorado Denver.

\section{References}

[1] Jacox, A. (1974) Theory Construction in Nursing: An Overview. Nursing Research, 23, 4-13. http://dx.doi.org/10.1097/00006199-197401000-00003

[2] Heartland National Tuberculosis Center (2010) Case Studies in Tuberculosis: Nurse Case Management Training Tools for Patient Success. http://www.heartlandntbc.org/products/case_studies_tb_ncm_training_tools.pdf

[3] International Council of Nurses (2008) Guidelines for Nurses in the Care and Control of Tuberculosis and Multi-Drug Resistant Tuberculosis. http://dph.georgia.gov/sites/dph.georgia.gov/files/TB-CMGuidelinesforCareofMDRTB.pdf

[4] Curtin, L. (1989) The Performance Edge. Nursing Management, 20, 7-13. http://dx.doi.org/10.1097/00006247-198902000-00001

[5] Owino, J. (2012) Owino’s Theory: Nurse-Client Interaction for Childbirth Preparedness Analysis and Evaluation. Lambert Academic Publishers, Deutschland.

[6] Alligood, M. (2013) Nursing Theorists and Their Work. 8th Edition, Mosby Elsevier.

[7] Wikipedia (2014) Florence Nightingale. http://en.wikipedia.org/wiki/Florence_Nightingale

[8] Sweet, V. (2014) Far More than a Lady with a Lamp. New York Times nytimes.com 2014 The New York Times Company, Page D3 of the New York Edition.

[9] Parker, M. and Smith, M. (2010) Nursing Theories and Nursing Practice. 3rd Edition, Davis, Philadelphia.

[10] Buhl, L., Howe, R., et al. (Students' Presenters and Discussants) to Geer Betty PhD and Sue Hagedorn (2014) Lecture Notes and Presentations. NURS 6012: Advanced Theory in Nursing. University of Colorado, Denver.

[11] Zignol, M., van Gemert, W., Dennis Falzon, D., Sismanidis, C., Philippe Glaziou, P., Floyda, K. and Raviglionea, M. (2012) Surveillance of Anti-Tuberculosis Drug Resistance in The World: An Updated Analysis, 2007-2010. Bulletin of the World Health Organization, 90, 111-119. http://dx.doi.org/10.2471/BLT.11.092585

[12] Ministry of Public Health and Sanitation, Kenya (2012) Standard Operating Procedures for Programmatic Management of Drug Resistant Tuberculosis_-(PMDT) Kenya. www.nltp.co.ke/docs/Standard_operating_Procedures.pdf

[13] Prof Tito's Unit, A Case of PUO. http://www.slideshare.net/smcmedicinedept/a-case-of-mdrtb

[14] WHO Global Tuberculosis Report 2013. http://apps.who.int/iris/bitstream/10665/91355/1/9789241564656_eng.pdf

[15] WHO Bulletin, 2012.

[16] MTRH Bulletin, 2010.

[17] WHO Bulletin, 2010. http://www.who.int/bulletin/volumes/90/2/11-092585.pdf

[18] WHO Fact Sheet No. 104. www.who.int/../en/

[19] Chinn, P. and Kramer, M. (2011) Integrated Theory and Knowledge Development in Nursing. 8th Edition, Elsevier Mosby, St. Louis.

[20] NALEP-TB (2014) National TB and Leprosy Program, Kenya

[21] Ministry of Health Pokot County (2013) Health at a Glance. http://www.healthpolicyproject.com/pubs/291/County\%20poster-factsheet_West\%20Pokot_FINAL_A3.pdf

[22] Gichuhi, A.W., Kamau, S.M., Nyangena, E.N. and Otieno-Ayayo, Z. (2015) Health Care Workers Adherence to Infection Prevention Practices and Control Measures: A Case of a Level Four District Hospital in Kenya. American Journal of Nursing Science, 4, 39-44.

[23] Peter, D. (2014) Incidence of Childhood Tuberculosis Could Be 25 Percent Higher than Previous Estimates. The Lan- 
cet Global Health Paper.

[24] Kenya National Assembly Official Record (n.d). http://www.parliament.go.ke/index.php/the-national-assembly/house-business/hansard

[25] Save the Children (2015) Save the Children Warns That "Terrifying Rate” of Spread Will Overwhelm... Ebola Is Spreading at the Rate of Five New Cases an Hour in Sierra Leone. http://www.savethechildren.ca/

[26] Nightingales Theory and Opening Windows to Control Pathogens.

http://www.theguardian.com/science/2012/feb/20/open-hospital-windows-stem-infections

[27] Maher, D., Blanc, L. and Raviglione, M. (2004) WHO Policies For Tuberculosis Control. The Lancet, 363, 1911. http://dx.doi.org/10.1016/s0140-6736(04)16377-0

[28] TBHIV Working Group. https://www.facebook.com/pages/TBHIV-Working-Group-of-the-STOP-TB-Partnership/106177126100931

[29] Nightingale, F. (1960) Notes on Nursing. What It Is, and What It Is Not. http://digital.library.upenn.edu/women/nightingale/nursing/nursing.html\#II

[30] Hagedorn, S. (1995) The Politics of Caring: The Role of Activism in Primary Care. Advances in Nursing Science, 17, 1-11. http://dx.doi.org/10.1097/00012272-199506000-00002

[31] Nightingale, F. (1894) Sick Nursing and Health Nursing. In: Billings, J. and Hurd, H., Eds., Hospitals, Dispensaries and Nursing: Papers and Discussions in the International Congress of Charities, Correction and Philanthropy, The Johns Hopkins Press, Baltimore.

[32] Wangari, D. (2014) Multi Drug Resistant TB Still a Menace. The Star. http://www.the-star.co.ke/news/article-158907/multi-drug-resistant-tb-still-menace\#sthash.to7BXBQL.dpuf

[33] AIDSPortal (2014) Kenya: XDR-TB Case Raises Questions. http://www.aidsportal.org/web/guest/resource?id=6897b08e-f1a8-457c-9e10-69d9da7e7aaa\#sthash.r71nNyIB.dpuf

[34] Nursing Theories (2011) A Companion to Nursing Theories and Models. http://currentnursing.com/nursing_theory/nursing theorists.html

[35] Theoretical Foundations of Nursing (2011) Florence Nightingale. Notes on Nursing. http://nursingtheories.weebly.com/florence-nightingale.html 